\title{
COMMUNICATIONS
}

\section{PROLIFERATIVE DIABETIC RETINOPATHY* EVOLUTION OF THE RETINAL LESIONS}

\author{
BY \\ J. H. DOBREE
}

St. Bartholomew's Hospital and North Middlesex Hospital, London

THE advent of proliferative retinopathy gravely influences the prognosis with regard to vision in a diabetic, and the management of this complication is one of the most difficult medical problems of the present time. The term proliferative retinopathy is here used in its widest sense, to include not only the more obvious neovascular and connective tissue lesions which arise from the disc area, but also the smaller collections of new vessels which appear in the superficial retinal capillary plexus. Proliferative diabetic retinopathy (P.D.R.) has a particularly complex fundus picture, for not only do the larger lesions project into the vitreous and acquire an extra dimension, but they are superimposed on a background of simple diabetic retinopathy which may be of any degree of severity. Superimposed on the proliferative vessels in their turn are subhyaloid and vitreous haemorrhages. In the final stages occlusions of the retinal vessels, retinal detachments, and secondary glaucoma complicate an already confused picture.

Observers vary greatly in their assessment of the incidence of the complication, presumably because some have accepted only the more florid examples in their patients. Thus, of the larger series reported in the last decade, Porstmann (1954) in a series of 720 diabetics found an incidence of P.D.R. of 1.7 per cent., Engelson (1954) in 623 diabetics found 4 per cent., and Dekking (1954) in 383 diabetics found 7 per cent. Higher rates are given by Kornerup (1958) 8.4 per cent. in 1,402 unselected diabetics, by Scott (1953) 9.7 per cent., and by Wilson, Root, and Marble (1951) $16 \cdot 3$ per cent. Root, Mirsky, and Ditzel (1959) estimated that it was found in one out of every five cases of diabetic retinopathy.

There is a familial tendency to P.D.R. as in simple diabetic retinopathy. Fischer (1954) found a family history of P.D.R. in 37.5 per cent. of cases, and Root and others (1959) in 52 per cent.

Since the first descriptions of new vessel and connective tissue formations in the retinae of diabetics by Manz (1876), a wealth of facts concerning the association of proliferative diabetic retinopathy (P.D.R.) and the general diabetic state has accumulated. It is well established that P.D.R. may occur at any stage of diabetes, but is most commonly found between the ages of 25 and 50, and particularly in those who have become diabetic before the age of 20 . Patients in whom the control of the diabetes has been unsatisfactory, either because of extreme variability of the insulin requirements ('labile' or 'brittle' diabetics) or because of failure to keep to dietary restrictions, are especially liable to develop the condition. It is also well known 
that there is a frequent association between P.D.R. on the one hand and hypertensive or arteriosclerotic vascular disease and renal disease on the other. It is not intended to review these general aspects in detail; they have been fully presented by Kornerup (1958) and Root and his co-workers (1959) among others.

It is, however, the fundus changes occurring in P.D.R. which are the main concern of this paper. There has been much speculation as to the sequence of events leading to the early proliferative lesions. Hanum (1938) summarized previous observations; the consensus of opinion of earlier workers was that the new vessel formations were secondary to retinal haemorrhages breaking through the internal limiting membrane. Hanum himself described a collection of fine new vessels emerging from the disc and growing towards a pre-retinal haemorrhage. The fact that new vessels can arise quite independently of haemorrhages was suggested by the observations of Klein (1938) and Salzmann (1939), later supported by Ballantyne (1946) and von Bahr (1947). The work of Ballantyne and Michaelson (1947) and of Michaelson (1948, 1954) on the formation of retinal vessels suggested new concepts of the origin of new vessel formations, and the more recent writers on proliferative retinopathy, such as Wise (1956) and Larsen (1960), have affirmed that the earliest proliferative lesion usually occurs in the form of groups of delicate brush-like new formed vessels which develop either from the vessels in front of the disc or from retinal vessels. In these early lesions the supporting connective tissue is scanty and almost transparent.

The transition from these fine vascular networks with scanty supporting connective tissue into larger proliferative masses in which connective tissue predominates has been demonstrated by Hanum (1938), who thought it probable that this stage represented the terminal state in the retinopathy; Klein (1938); and Wise (1956); and was photographed by Larsen (1959), who showed several examples of the extensive connective tissue formations which form in the later stages, with the traction and wrinkling of the hyaloid membrane associated with contracture of these connective tissue bands. The retinal veins are frequently grossly distorted by these traction effects (Hanum, 1938) and may be actually drawn forward out of the retina (Davanger, 1961). The retina itself may be detached by traction bands (Gartner, 1950 and others). Vitreous haemorrhages are common at this stage, and Wise notes that after clearing there is often "a heavy fibrosis with a lighter vascular element mainly at the disc and posterior pole of the eye".

Spontaneous remissions of the proliferative lesions have occasionally been reported. Disappearance of the early vascular networks, both on the disc and in the retina, was photographed by Larsen (1959). In later stages in severely affected eyes, the clearing of haemorrhages and a dramatic improvement of vision lasting for several years was noted by Babel and Rilliet (1958), Fischer (1961), and Beetham (1963); the last noted that a quiescent stage may be reached in which vitreous haemorrhages cease, the retinal vascular picture becomes quiescent, the proliferative tissue thins and becomes reticulated, and the veins lose their distended appearance.

The histology of the proliferative lesions of P.D.R. has been studied in stained sections by Klein (1938) and others, by injection techniques by Ashton (1951), and by digestion techniques by Cogan, Toussaint, and Kuwabara (1961). Mast cells have been demonstrated in eyes with advanced diabetic retinopathy by Linnér and Tengroth (1962). 
Proliferative changes usually occur on a background of simple diabetic retinopathy which may be of any degree of severity. In general these changes are most marked in older patients. Scott (1951) and Ehlers (1953) stress that proliferative lesions represent a different disease process from the lesions of simple retinopathy and do not derive from them. Cogan and others (1961) remarked that they "would agree with the statement that R.P. was a variant, to be sure a serious one of diabetic retinopathy, rather than the end stage of the other types".

\section{Present Investigation}

The purpose of the present work was to study the evolution of all stages of P.D.R., both on the disc and in the retina, in a number of eyes by serial fundus photographs in order to see if any regular pattern of change emerged in a series of untreated cases.

\section{Clinical Material}

25 eyes showing lesions of P.D.R. came from a series of fifteen patients. Inclusion in the series was decided by whether or not first order photographic observations had been made at sufficiently frequent intervals to ensure that the changes which took place could be accurately followed. The five eyes which were excluded all had vitreous haemorrhages, either at the initial examination or early in the period of observation.

Table I (overleaf) gives the clinical details of the fifteen patients. Although small the group seems to be a representative sample of the diabetic population in which proliferative changes may be expected; it will be noted, however, that males predominate in this group in the ratio of 12:3-instead of the more usual slight predominance of females. Five of the patients were over the age of 50 years.

Apart from care in control of the diabetes no special treatment was given, except that three patients, recorded in the last column in Table I, were given $10 \mathrm{mg}$. prednisolone daily approximately half-way through their period of observation. It is not thought likely that it had any effect on the character of the lesions, but it is possible that it may have influenced the rate of their evolution.

Table II (overleaf, p. 642, 643) shows in the left-hand columns the length of time that each fundus was observed and the number of observations made. The average interval between the photographs was 3 to 4 months, but photographs were taken at shorter intervals if important changes were occurring. Two or three fields were usually observed. The disc area was always photographed, and if possible the upper temporal and lower temporal fields in a view which included macula, disc, and first and second vessel branchings, other fields being photographed if interesting lesions were evolving. The Zeiss fundus camera was used in all cases, and all photographs were made either by the author or by an assistant under his supervision. The result was that identical fields were usually secured and exact comparisons could be made. The greatest number of observations was three fields, each photographed on twelve occasions, spread over 3 years, and the least was three fields photographed on three occasions over 6 months.

It is realized that fundus photographs can give misleading information, particularly if they show formations lying in different planes in the vitreous. Fundus cameras give little depth of focus, and it is possible to obtain an effect of appearance and disappearance of groups of vessels by small variations in focus or exposure. Connective tissue formations may also appear to alter in size and density in serial photographs for the same reasons. Sometimes, in the later stages, fan-shaped proliferations may alter their plane in relation to the retina, and if viewed end-on, may appear denser and less vascular than when seen on the flat. 
TABLE I

GENERAL CLINICAL DATA REGARDING PATIENTS

\begin{tabular}{|c|c|c|c|c|c|c|c|c|c|}
\hline $\begin{array}{l}\text { Case } \\
\text { Number }\end{array}$ & Sex & $\begin{array}{c}\text { Age at } \\
\text { Original } \\
\text { Observa- } \\
\text { tion } \\
\text { (yrs) }\end{array}$ & $\begin{array}{c}\text { Interval } \\
\text { since } \\
\text { Recogni- } \\
\text { tion of } \\
\text { Diabetes } \\
\text { (yrs) }\end{array}$ & $\begin{array}{c}\text { Insulin } \\
\text { Dosage } \\
\text { (approx. } \\
\text { units/day) }\end{array}$ & $\begin{array}{c}\text { Control } \\
\text { of } \\
\text { Diabetes }\end{array}$ & $\begin{array}{c}\text { Blood } \\
\text { Pressure }\end{array}$ & $\begin{array}{l}\text { Arterio- } \\
\text { sclerotic } \\
\text { Disease }\end{array}$ & $\begin{array}{l}\text { Renal } \\
\text { Involve- } \\
\text { ment }\end{array}$ & $\begin{array}{l}\text { Predni- } \\
\text { solone }\end{array}$ \\
\hline 1 & $M$ & 72 & 5 & 20 & Good & $180 / 110$ & Nil & Nil & \\
\hline 2 & $\mathbf{M}$ & 26 & 18 & 40 & Poor & $220 / 110$ & $\mathrm{Nil}$ & Advanced & \\
\hline 3 & $\mathrm{M}$ & 50 & $0 \cdot 1$ & Nil & Good & $190 / 110$ & Nil & Nil & \\
\hline 4 & $\mathrm{M}$ & 40 & $0 \cdot 8$ & 140 & Moderate & $135 / 80$ & Nil & Nil & \\
\hline 5 & $\mathrm{~F}$ & 56 & 3 & 45 & Moderate & $210 / 120$ & $\begin{array}{l}\text { Myocardial } \\
\text { damage }\end{array}$ & Nil & \\
\hline 6 & $F$ & 30 & 26 & 100 & Poor & $155 / 75$ & $\begin{array}{l}\text { Died of } \\
\text { coronary } \\
\text { thrombosis }\end{array}$ & Moderate & $\mathrm{P}$ \\
\hline 7 & $\mathrm{M}$ & 33 & 24 & 40 & Moderate & $140 / 110$ & Nil & Nil & $\mathbf{P}$ \\
\hline 8 & $\mathrm{~F}$ & 47 & 15 & 70 & Moderate & $110 / 75$ & Nil & Nil & \\
\hline 9 & $\mathrm{M}$ & 59 & 5 & 30 & Good & $170 / 90$ & Nil & Nil & \\
\hline 10 & $\mathrm{M}$ & 29 & 28 & 60 & Poor & $155 / 100$ & Nil & Slight & \\
\hline 11 & $\bar{M}$ & 40 & 20 & 50 & Good & $140 / 80$ & Nil & Nil & \\
\hline 12 & $\mathbf{M}$ & 32 & 30 & 90 & Poor & $140 / 90$ & Nil & Slight & \\
\hline 13 & $\bar{M}$ & 61 & 4 & 40 & Moderate & $180 / 90$ & $\begin{array}{l}\text { Obliterative } \\
\text { arterial } \\
\text { disease }\end{array}$ & Nil & \\
\hline 14 & $\bar{M}$ & 36 & 25 & 90 & Moderate & $170 / 100$ & Nil & Nil & $P$ \\
\hline 15 & $\mathbf{M}$ & 39 & 28 & 70 & $\begin{array}{l}\text { Poor, later } \\
\text { good }\end{array}$ & $160 / 100$ & Nil & Nil & \\
\hline
\end{tabular}

The background retinopathy, which is always of interest, is briefly described in a separate column in Table II (overleaf); its severity varied greatly from case to case.

\section{FINDINGS}

Proliferative lesions were found in association with vessels in the disc area, or with retinal vessels elsewhere in the fundus, as described by Ballantyne and Michaelson (1947). In both situations the lesions passed through three well-defined stages:

I. They always commenced with a collection of fine naked vessels;

II. They then passed through a stage of vascular proliferation with connective tissue formation;

III. They entered a stage of regression of the vessel systems and contracture of connective tissue elements. 
The disc lesions usually dominate the picture, but the retinal lesions are the more numerous.

The fundus conditions in the 25 eyes are set out in Table II (overleaf).

\section{Disc Lesions}

Stage I. Formation of Naked Vessels.-This development on a disc originally perfectly free of new vessels was observed and photographed on seven occasions. The earliest disc lesions seen to develop took the form of fine brush-like collections of capillaries lying on the surface of the disc. These minute new vessels arose from the capillary network normally found on the surface of the disc, but soon established connexions with the larger veins on the disc. These first vessels were quite naked, in that there was no evidence of any associated connective tissue. Later, the vessels, still naked, increased in size and number until the subhyaloid space immediately in front of the disc became covered with a fine network of ramifying vessels; these are the "pre-papillary networks" recorded in Table II. No haemorrhages were observed preceding or in association with the earlier vessels, but small haemorrhages were often seen among the new vessels as the networks became larger. This phase lasted some 6 to 18 months in the cases observed, and all these seven cases passed on to the next stage.

Stage II. Vascular Proliferation and Connective Tissue Formation.-The evolution of this stage from Stage I was observed and photographed in ten eyes.

The pre-papillary networks in no case remained confined to the disc area, but extended rapidly. In the plane of the retina the extension tended to be in the direction of the main trunks of the retinal vessels, but the most exuberant extensions proliferated into the vitreous, forming arcade upon arcade of festooning vascular loops in many planes. The vessels feeding and draining the larger systems often approached in size the normal retinal vessels. Throughout this stage connective tissue condensations appeared around the vessels. These first showed as cloud-like condensations among the vessels of the pre-papillary networks and often consolidated in the form of vertically disposed bands in the plane of the retina. The vitreous proliferations too had their condensations, particularly among the older vessels at their bases; the newer arcades of new vessels were naked, but even these could be seen on Hruby lens examination to have a fine filmy condensation of vitreous preceding them. At this stage the vascular element was at its most exuberant stage, and the blood vessels dominated the fundus picture. Haemorrhages were especially common at this stage from the very numerous rapidly growing thin-walled vessels. A large vitreous haemorrhage sometimes occurred, and repeated vitreous haemorrhages filled the eye with clot, obscured all further observations, and marked the final state of the eye. This happened in the five eyes for which no observations can be given. More often subhyaloid haemorrhages developed or small extravasations among the network vessels. This phase lasted from 1 to 2 years and gradually merged into the third stage. 


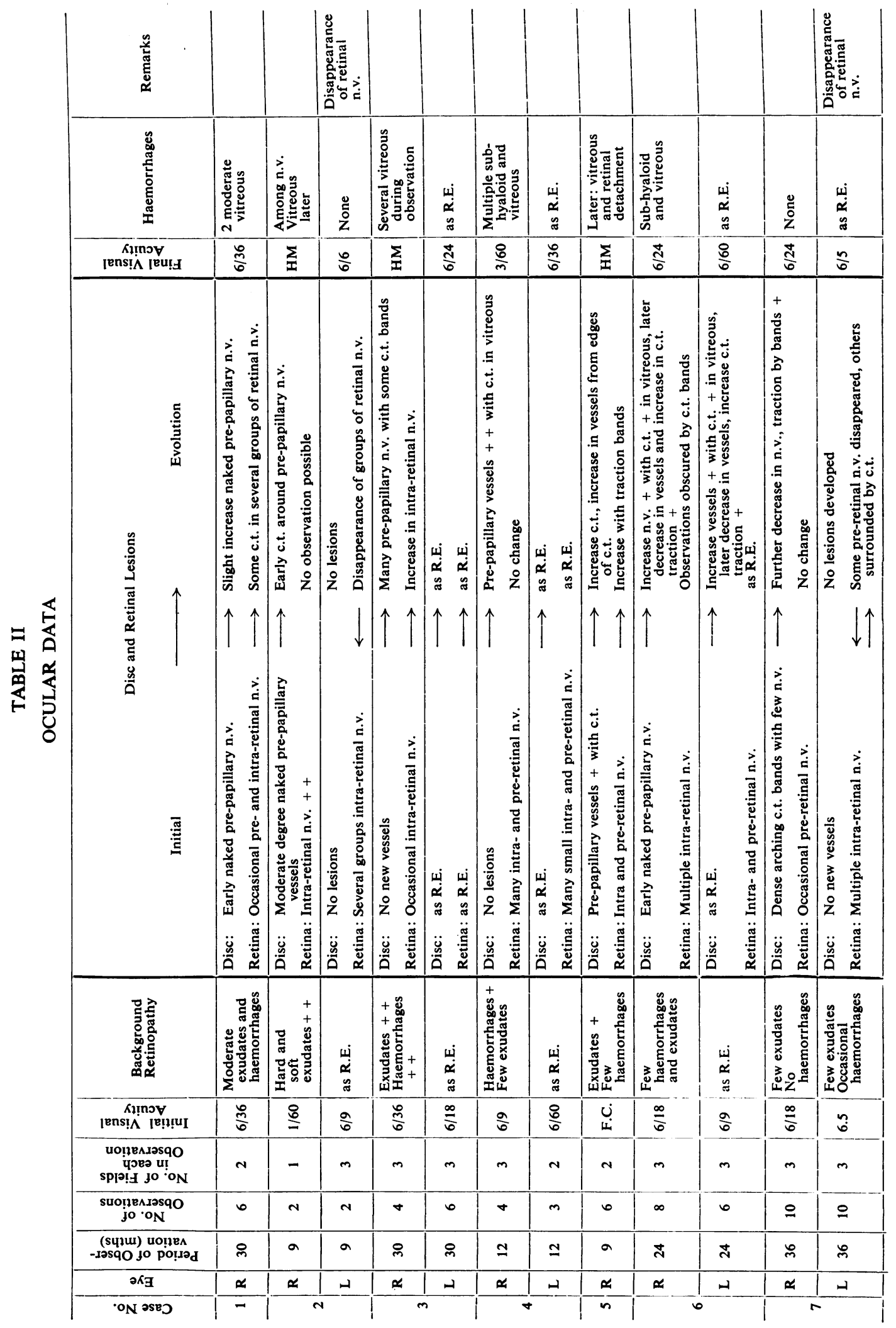




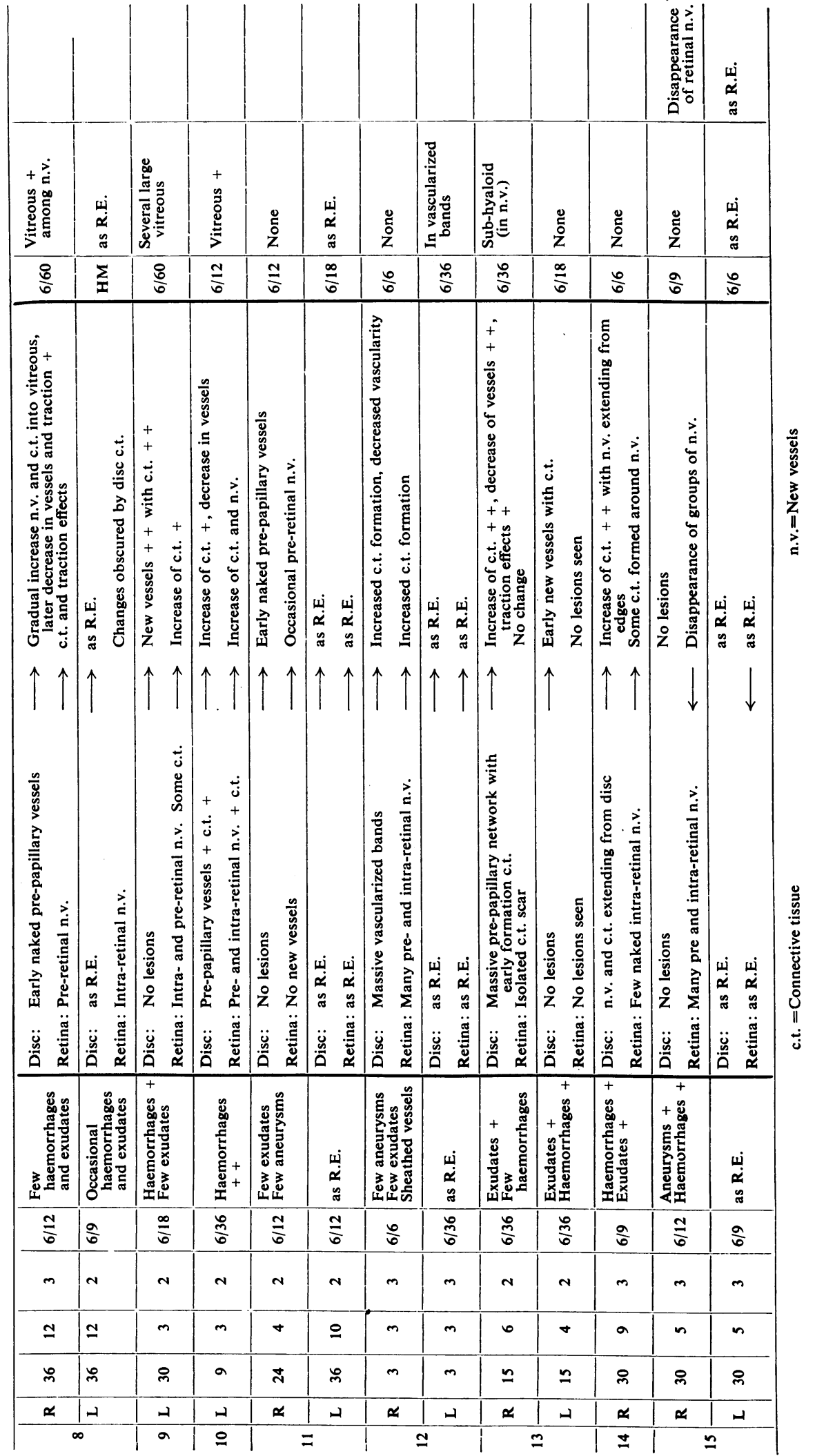


Stage III. Regression of the Vascular Systems and Connective Tissue Contracture.The evolution of this stage from Stage II was observed and photographed in twelve eyes.

The vascular elements finally reached their maximum development and slowly atrophied, and at the same time the connective tissue elements condensed, so that the final fundus picture took the form of dense white sheets of connective tissue with relatively few vessels in their substance. This connective tissue slowly contracted and when this happened secondary effects occurred. In the first place there was often considerable distortion of the course of the normal retinal vessels. In Case 8, for example, the main trunk of the inferior retinal veins of the right eye was dragged a disc diameter to the temporal side of its original course, and in Case 7 the inferior temporal vein of the right eye was dragged bodily out of the retina by a dense contracture band. In several eyes, arching connective tissue bands covering the upper and lower groups of temporal vessels caused a wrinkling of the retina and in one case the macula was displaced. No traction detachments were caused by disc vessels in this group of cases.

This process, it must be emphasized, was very gradual, and although the overall trend was towards an increase in the density of the connective tissue and a decrease in the vascular elements, fresh secondary vascular arcades often started proliferating from the older new vessels rather in the manner of a smouldering heath-fire with its tendency to fresh outbreaks before dying out. Most of the cases could be classed as being only in the early phases of Stage III, but four of the twelve eyes showed very dense connective tissue formations. No case in this series showed what has been reported as an even later stage in the connective tissue formations, that is an actual decrease in their density. Beetham (1963), for example, reported this as occurring spontaneously in one of his cases. Haemorrhages were less common when the eyes had reached this stage, and defects in vision were due to mechanical obstruction by connective tissue and possibly to traction effects also.

\section{Retinal Lesions}

The retinal lesions were associated with retinal vessels and were usually situated between the disc and the equator. They were frequently multiple and were of two distinct types, intra-retinal and pre-retinal, depending on whether or not the internal limiting membrane had been penetrated. These retinal lesions were more common than the disc lesions, and the same three stages could be made out.

Stage I. Formation of Naked Vessels.-Seventeen of the 25 eyes were found to have one or more groups of naked intra-retinal and pre-retinal new vessels in the initial photographs. Three distinct types of retinal new vessels were noted, and they conformed to the arrangements described by Ashton (1951) and Larsen (1960):

(a) Small collections of vascular arcades;

(b) Clusters of tightly-packed capillaries in rosette form;

(c) Groups of anastomotic vessels surrounding sectors of vessels, presumably forming a collateral circulation.

Both intra- and pre-retinal new vessels were most commonly seen in areas where the retinal veins showed pathological changes. In six cases they preceded the 
formation of the new vessels on the disc and in a further three were the only evidence of P.D.R. In four cases (described later) certain groups disappeared completely. It is probable that, if the whole fundus had been photographed in each case, the incidence would have been found to have been very much higher. These naked retinal new vessels would therefore seem to be the earliest type of proliferative lesion, and the intra-retinal type have been observed in these and other cases to remain in much the same form for several years.

Stage II. Vascular Proliferation and Connective Tissue Formations.-The intraretinal groups of vessels increased only slowly in size, but later tended to have fine condensations of connective tissue around them; the pre-retinal groups often proliferated extensively as ramifying networks in front of the retina, and connective tissue also developed around them later. In this particular series no large proliferations occurred into the vitreous from primary retinal lesions, but in one case a finger-like process consisting of lightly packed vessels surrounded by closely knit connective tissue protruded from a retinal focus into the vitreous.

Stage III. Regression of Vascular Systems and Connective Tissue Contracture.Where connective tissue formations occurred, especially in flat sheets in front of the retina, these later became gradually less vascular and local traction effects occurred. Sometimes the gross displacement of large vessels completely altered their course over a sector. A more dangerous development, seen in Case 5, was an actual tearing of the retina with subsequent detachment; a large localized band had developed across the line of the lower temporal vessels some four disc diameters from the disc; this contracted downwards pulling down the vessels and causing the development of a series of holes below the macula.

Stages Observed in Individual Cases.-Table III (overleaf) shows the stages in retinal and disc lesions observed in each eye. As the lesions usually take some 5 years to advance from mild to severe (Beetham, 1963) and the patients in this series were under observation for only 6 months to 3 years, it is clear that only a part of the cycle was observed in any particular case. Table III demonstrates that (with the exception of the four cases showing complete disappearance of new vessels) if a case was observed to be in one stage it proceeded to the next.

Rates of Progress of Disc and Retinal Lesions.-Table III also shows that, whereas at the initial examination 24 of the 25 eyes showed retinal lesions only seventeen showed disc changes. However, six of these cases showing disc lesions were observed to pass through all three stages, whereas only two of those initially showing retinal lesions were observed in all stages. This is because the retinal lesions were slower to evolve than those on the disc.

Symmetry of Lesions. - In Case 7 the right eye showed advanced Stage II disc lesions at the first examination and the left eye showed numerous Stage I intra-retinal lesions. Case 2 in which the diabetes was complicated by hypertension, showed a progression from Stage I to Stage II in the disc vessels of one eye, while retinal (intra-retinal anastomatic) lesions regressed in the other. In the other eight patients in whom both eyes could be observed, the retinal and disc lesions were similar in type and extent. 
TABLE III

STAGES OBSERVED IN INDIVIDUAL EYES

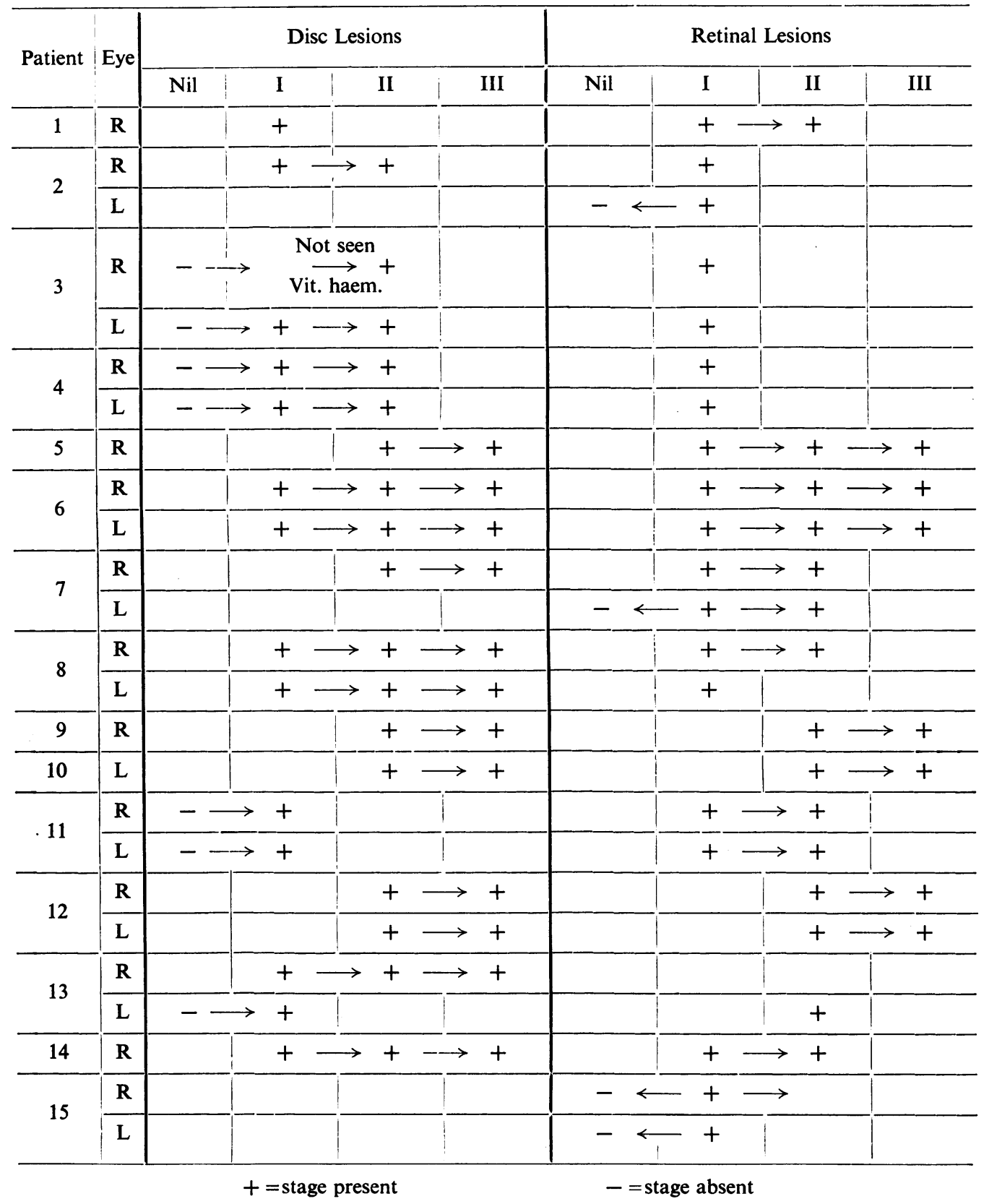

Disappearance of Lesions.-This occurred in four cases.

Case 2. This eye has already been mentioned. A group of anastomatic intraretinal vessels which had formed in association with a grossly distended vein was 
observed to regress entirely. This coincided with a dramatic improvement in the patient's hypertension and renal condition with rest and treatment.

Case 7.-Several smaller groups of intra-retinal vessels completely disappeared while some larger groups of pre-retinal vessels lying nearby in the same sector passed into Stage II.

Case 15.-Both eyes had multiple groups of new vessels when seen by the writer in 1957; they were photographed 4 years later and 2 years after this photographs showed that the new formed vessels previously visible had disappeared and ophthalmoscopic observation confirmed an almost complete regression. The patient had no treatment other than a careful control of his diabetes when his predicament was explained to him after his initial examination.

Haemorrhages.-These are the ever-present dread both of patient and oculist when P.D.R. is present. Only ten eyes out of thirty remained clear of haemorrhages from the new vessels. The serial photographs demonstrated that haemorrhages are most likely to occur late in Stage I and in Stage II. Small haemorrhages among the new formed vessel plexuses were very common and often passed unnoticed by the patient. Larger subhyaloid haemorrhages were also common; they often formed large lakes of blood up to 2 or 3 disc diameters in extent and took several months to absorb. Subhyaloid haemorrhages running in linear form for 1 to 3 disc diameters below a main vein were also seen on three occasions. Vitreous haemorrhages may cause a speedy and permanent loss of vision as happened in the five eyes excluded from the series, but three other eyes weathered the storm of large haemorrhages; they took several months to clear, but eventually the eyes retained some vision. Haemorrhages are especially liable to occur during exertion, particularly that involving bending and stooping, and patients should be warned against this. Case 8, for example, when in the early second stage, had severe vomiting caused by gastritis, which caused numerous subhyaloid haemorrhages to occur in the new vessel plexuses in front of both discs. Case 12, an early Stage III, noticed diminution of vision in one eye after changing a car tyre. This was caused by the rupture of a dozen or more small capillaries remaining in dense sheets of connective tissue. Despite this case it was found that, on the whole, bleeding was much less common in eyes which had reached Stage III.

Thickenings of Hyaloid Membrane.-Changes were observed which appear to be due to increased density of tissue in the vicinity of the hyaloid membrane.

In the central area of several eyes, fine sheets of thickening formed in the region of the posterior pole. They sometimes appeared as terminal extensions of the connective tissue bands which form arches along the course of the upper and lower temporal vessels. However, these hyaloid thickenings described by Larsen (1960), were avascular from the start.

Another appearance which also seems to be due to a hyaloid thickening is the occurrence of a dense band of connective tissue stretching as a long thin white cord across the subhyaloid space. These were found twice in this series. They are 
avascular and may run in any direction for 2 to 3 disc diameters or more, terminating at either end in rather indefinite loose connective tissue formations on the retina.

Changes in the Retinal Vessels. - Sheathing of both veins and arteries with narrowings of their blood column was sometimes found in Stage III, but this may have been due to obliterative changes in the vessels themselves, and was not necessarily caused by the proliferative lesions.

Changes in Visual Acuity.-The initial and final visual acuities are given in Table II. Twelve of the 25 eyes became worse and seven better, and six were unchanged.

Background Retinopathy.-Apart from one eye (the left eye in Case 2), in which the new vessels disappeared when the patient's general condition improved, and the eyes of two of the older patients (Cases 3 and 13), in which the diabetic exudates increased, there were the usual minor fluctuations in haemorrhages and exudates but no great overall differences in the background retinopathy.

\section{Discussion}

Although the development of each stage of proliferative retinopathy has previously been described, it has not hitherto been established that both the disc and retinal lesions form and evolve in the three consecutive stages that this serial photographic record has shown. At the present time proliferative lesions, formerly held to lie outside the range of therapy, are being attacked from several fronts with varying degrees of success. For example, the methods of pituitary ablation initiated by Luft, Olivecrona, Kornerup, Ljunggren, Nilsson, and Sjögren (1956), the lightcoagulation techniques of Meyer-Schwickerath (1960) and Wetzig and Worlton (1963), and the anabolic steroids used by Valk (1960) aim at causing regression of the proliferative lesions. It is of paramount importance therefore, in assessing the effectiveness of treatment, to recognize that Stage III of the spontaneous changes shows a reduction in new vessels and probably a reduction in the tendency to haemorrhages.

Complete disappearance of groups of both retinal lesions and disc lesions has been previously reported by Larsen $(1959,1960)$. The present series again shows spontaneous regression of small groups of retinal vessels but no regression of disc lesions was noted. The case with asymmetrical lesions in the two eyes is of particular interest, and similar isolated cases have been reported by Hanum (1938), Klein (1938), and Larsen (1959). Further, the fact that, in the same eye, some of the lesions may be in the final stage, while others are in the early stage, would seem to suggest that proliferative lesions comprise a series of changes caused by focal retinal conditions rather than a response to a generalized systemic disturbance. The striking association of retinal lesions with pathological changes in the visible retinal veins amply confirms the observations of Ballantyne (1946), Scott (1951), Kornerup (1958), and Larsen (1959). The anatomical study of the formation and evolution of the lesions yields no information regarding the factor exciting the changes, but the response is similar to the three stages of granulation tissue: new vessels, connective tissue formation, and fibrosis. 


\section{Summary}

25 eyes from fifteen patients suffering from proliferative diabetic retinopathy have been studied by serial fundus photographs for a period of 6 to 36 months.

Three stages were formed in the development of the lesions, whether these occurred from the vessels in the vicinity of the disc, or from retinal foci:

I. The development of delicate vessels with scanty connective tissue (naked vessels).

II. An increase in the number and size of the proliferating vessels and condensations of connective tissue around them.

III. A regression of the vascular systems and contracture of the connective tissue.

The retinal new vessels are often stable for a considerable length of time and in four eyes a complete disappearance of some of the lesions was noted.

Certain cases showed some lesions to be in an early stage, whilst others were in a late stage either in the same or the fellow eye.

Vitreous haemorrhages occurred most frequently in the later period of Stage I and in Stage II.

My thanks are due to Dr. Kenneth Black, physician in charge of the Diabetic Clinic at St. Bartholomew's Hospital, for his interest and help in this investigation, to Mrs. E. M. L. Cole for taking many of the fundus photographs and for her care in record keeping, and to Miss T. Lister for her work in the preparation of this paper.

\section{REFERENCES}

Ashton, N. (1951). Proc. roy. Soc. Med., 44, 747. (1959). Lancet, 2, 625.

BABEL, J., and RILLIET, B. (1958). Ophthalmologica (Basel), 135, 471.

BAHR, G. VON (1947). Acta med. scand., Suppl. 196, p. 24.

BallantYNe, A. J. (1946). Trans. ophthal. Soc. U.K., 66, 503.

- and MiChaELSON, I. C. (1947). In "Modern Trends in Ophthalmology", ed. A. Sorsby, vol 2, pp. 262-281.

BeEtham, W. P. (1963). Brit. J. Ophthal., 47, 611.

Cogan, D. G., Toussaint, D., and Kuwabara, T. (1961). A.M.A. Arch. Ophthal., 66, 366.

Davanger, M. (1961). Acta ophthal. (Kbh.), 39, 1.

DeKkING, H. M. (1954). Trans. ophthal. Soc. U.K., 74, 499.

EHLERS, H. (1953). Acta ophthal. (Kbh.), 31, 289.

ENGELSON, G. (1954). Acta paediat. (Uppsala), Suppl. 97.

Fischer, F. (1954). Klin. Mbl. Augenheilk., 125, 666. (1961). v. Graefes Arch. Ophthal., 163, 397.

GARTNER, S. (1950). Amer. J. Ophthal., 33, 727.

HaNum, S. (1938). Acta ophthal. (Kbh.), Suppl. 16.

KLEIN, B. A. (1938). Arch. Ophthal. (Chicago), $20,427$.

KORNERUP, T. (1958). Acta ophthal. (Kbh.), 36, 87.

LARSEN, H. W. (1959). Ibid., Suppl. 55. (1960). Ibid., Suppl. 60.

LiNNÉR, E., and TENGROTH, B. (1962). I Ibid., 40, 266-270.

Luft, R., Olivecrona, D., Kornerup, T., LJungGren, H., Nilsson, L. B., and SJögren, B. (1956). Nord. Med., 55, 715.

Manz, W. (1876). v. Graefes Arch. Ophthal., 22 (ii), 229.

MEYER-SCHWICKERATH, G. (1960). "Light-Coagulation", trans. S. M. Drance. Mosby, St. Louis.

MiCHAELSON, I. C. (1948). Trans. ophthal. Soc. U.K., 68, 137. (1954). "Retinal Circulation in Man and Animals". Thomas, Springfield, Ill.

Porstmann, W. (1954). Klin. Mbl. Augenheilk., 125, 336.

ROoT, H. F., MIRSKY, S., and DitZEL, J. (1959). J. Amer. med. Ass., 169, 903.

SalzmanN, M. (1939). v. Graefes Arch. Ophthal., 140, 629.

ScotT, G. I. (1951). Proc. roy. Soc. Med., 44, 743. (1953). Brit. J. Ophthal., 37, 705.

VALK, L. E. M. (1960). Ophthalmologica (Basel), 139, 480.

WETzIG, P. C., and Worlton, J. T. (1963). Brit.J. Ophthal., 47, 539.

WiLSON, J. L., ROOT, H. F., and MARBLE, A. (1951). Amer. J. med. Sci., 221, 479.

WiSE, G. (1956). Trans. Amer. ophthal. Soc., 54, 729. 